\title{
Ground-based intercomparison of two isoprene measurement techniques
}

\author{
E. Leibrock ${ }^{1,2,}{ }^{*}$, L. G. Huey ${ }^{3}$, P. D. Goldan ${ }^{1,2}$, W. C. Kuster ${ }^{1,2}$, E. Williams ${ }^{1,2}$, and F. C. Fehsenfeld ${ }^{1,2}$ \\ ${ }^{1}$ Aeronomy Laboratory, Environmental Research Laboratories, NOAA, Boulder, Colorado, USA \\ ${ }^{2}$ Cooperative Institute for Research in Environmental Sciences, University of Colorado, Boulder, Colorado, USA \\ ${ }^{3}$ School of Earth and Atmospheric Sciences, Georgia Institute of Technology, Atlanta, Georgia, USA \\ * present address: The Boston Consulting Group, Ludwigstraße 21, D-80539 München, Germany
}

Received: 11 March 2002 - Published in Atmos. Chem. Phys. Discuss.: 24 June 2002

Revised: 22 December 2002 - Accepted: 22 December 2002 - Published: 3 February 2003

\begin{abstract}
An informal intercomparison of two isoprene $\left(\mathrm{C}_{5} \mathrm{H}_{8}\right)$ measurement techniques was carried out during Fall of 1998 at a field site located approximately $3 \mathrm{~km}$ west of Boulder, Colorado, USA. A new chemical ionization mass spectrometric technique (CIMS) was compared to a wellestablished gas chromatographic technique (GC). The CIMS technique utilized benzene cation chemistry to ionize isoprene. The isoprene levels measured by the CIMS were often larger than those obtained with the GC. The results indicate that the CIMS technique suffered from an anthropogenic interference associated with air masses from the Denver, CO metropolitan area as well as an additional interference occurring in clean conditions. However, the CIMS technique is also demonstrated to be sensitive and fast. Especially after introduction of a tandem mass spectrometric technique, it is therefore a candidate for isoprene measurements in remote environments near isoprene sources.
\end{abstract}

\section{Introduction}

Isoprene is a $\mathrm{C}_{5} \mathrm{H}_{8}$ hydrocarbon that is emitted in large quantities by deciduous trees and other plant species, (e.g. Singh and Zimmerman, 1992; Steinbrecher, 1997). Isoprene reacts at the gas kinetic rate with the $\mathrm{OH}$ radical and has an atmospheric lifetime of approximately two hours during the day. Consequently, isoprene plays an important role in the production of secondary pollutants such as ozone, PAN, and CO (Atkinson, 1990; Montzka et al., 1993). Isoprene mixing ratios in the lower atmosphere vary from a few pptv to several ppbv and depend on factors such as land use, season, and temperature. Isoprene also reacts with ozone, which provides an important loss mechanism during the night. A detailed review of the atmospheric chemistry of isoprene as well as

Correspondence to: E. Leibrock (edel@eleibrock.de) estimates of the global emissions is given in Fehsenfeld et al. (1992).

In order to better understand oxidant formation on local and regional scales, reliable airborne measurements of the temporal and spatial distribution of isoprene are needed, requiring senitive, fast time response $(t \sim 1 \mathrm{~s})$ techniques. We developed a chemical ionization mass spectrometric method (CIMS) for the detection of isoprene in ambient air (Leibrock and Huey, 2000). CIMS techniques are generally known for their high time resolution and good sensitivity and have been applied to measure a number of different trace gases, including nitric and formic acid (Huey and Lovejoy, 1996), OH (Eisele et al., 1994), ammonia, acetonitrile, acetone (Arnold and Hauck, 1985), and various other organic compounds (Hansel et al., 1995); (Lindinger and Hansel, 1997). The goal of this study is to characterize the CIMS isoprene measurement by comparison with a well-established gas chromatographic (GC) technique (Goldan et al., 2000).

\section{Experimental section}

\subsection{Intercomparison location and time frame}

Isoprene measurements were performed on 18, 29, and 30 September and 01 October 1998 at the Enchanted Mesa field site located $\sim 3 \mathrm{~km}$ west of Boulder, Colorado at $1770 \mathrm{~m}$ above mean sea level in the foothills of the Rocky Mountains at the northwest edge of the Denver metropolitan area. At this location mixing ratios of VOCs such as isoprene can vary by orders of magnitude within a short time frame. These variations are primarily due to wind speed and direction and to a lesser extent to other factors such as temperature and precipitation. When the wind is from the west, clean air with low isoprene mixing ratios is transported to the site from the mountains. When the wind is from the urban areas to the south or east, large VOC loadings and high lev- 


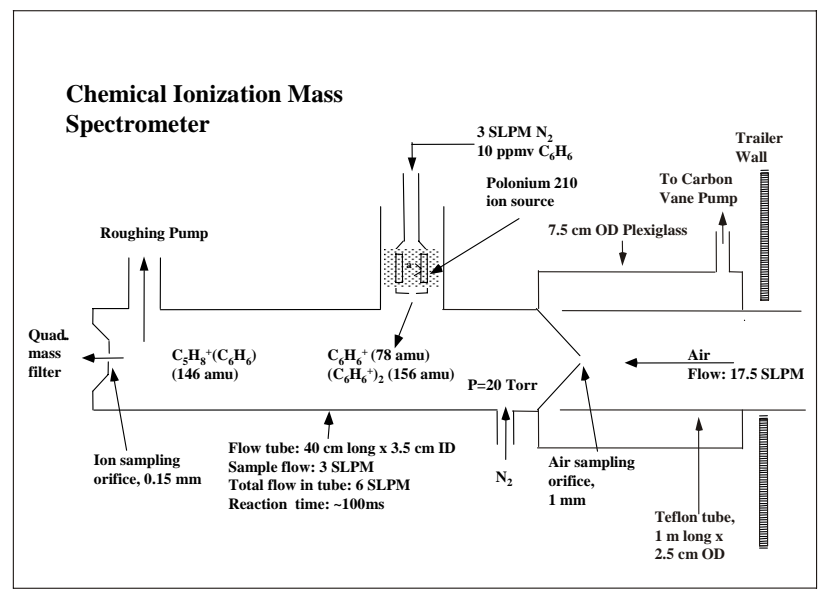

Fig. 1. Simplified schematic drawing of the chemical ionization mass spectrometer (CIMS).

els of other pollutants such as nitrogen oxides can be transported to the site. Consequently, the site is well suited for a challenging instrument intercomparison and has been used for this purpose on previous occasions (Fehsenfeld et al., 1998; Williams et al., 1992). Ancillary measurements of a wide range of chemical species and meteorological parameters were also performed during the intercomparison.

\subsection{CIMS}

The CIMS instrument was located in a trailer on the mesa. The air sampling inlet extended horizontally $\sim 50 \mathrm{~cm}$ from the west wall of the trailer at a height of $\sim 2 \mathrm{~m}$ above the ground. The inlet consisted of a $1 \mathrm{~m}$ long $\times 2.5 \mathrm{~cm}$ OD Teflon tube in which a flow of 17.5 SLPM (standard liters per minute) was maintained with a carbon vane pump. A small fraction of the total inlet flow, 3 SLPM, was sampled into the CIMS. The CIMS consisted of a flow tube reactor that was coupled to a quadrupole mass spectrometer (Fig. 1). The flow tube was equipped with a radioactive ion source $\left({ }^{210} \mathrm{Po}, \mathrm{NRD}\right)$ and a $1 \mathrm{~mm}$ diameter air sampling orifice. A total pressure of 20 Torr was maintained in the flow tube by a rotary vane pump. Benzene monomer and dimer cations, $\mathrm{C}_{6} \mathrm{H}_{6}^{+}$and $\left(\mathrm{C}_{6} \mathrm{H}_{6}^{+}\right)_{2}$, were synthesized by flowing $\sim 3$ SLPM of nitrogen doped with $\sim 10 \mathrm{ppmv}$ benzene vapor through the ion source into the flow tube reactor. The constituents of the sampled air reacted with the benzene cations along the length of the flow tube (reaction time $\sim 100 \mathrm{~ms}$ ). The resulting ions were sampled into the mass spectrometer where they were mass filtered and detected with an ion multiplier. The pulses from individual ions were amplified, counted, and stored in a computer.

Isoprene reacted by charge transfer association reaction with the benzene reagent ions (Leibrock and Huey, 2000):

$$
\begin{aligned}
& \mathrm{C}_{6} \mathrm{H}_{6}^{+}+\mathrm{C}_{5} \mathrm{H}_{8} \rightarrow \mathrm{C}_{5} \mathrm{H}_{8}^{+}\left(\mathrm{C}_{6} \mathrm{H}_{6}\right) \\
& \left(\mathrm{C}_{6} \mathrm{H}_{6}\right)_{2}^{+}+\mathrm{C}_{5} \mathrm{H}_{8} \rightarrow \mathrm{C}_{5} \mathrm{H}_{8}^{+}\left(\mathrm{C}_{6} \mathrm{H}_{6}\right)+\mathrm{C}_{6} \mathrm{H}_{6}
\end{aligned}
$$

Both benzene reagent ions react at collision rate with isoprene to form the same product ion, $\mathrm{C}_{5} \mathrm{H}_{8}^{+}\left(\mathrm{C}_{6} \mathrm{H}_{6}\right)$, at $146 \mathrm{amu}$. Isoprene sensitivity was not affected by ambient humidity levels; water clusters were not observed for either benzene cation (Leibrock and Huey, 2000). Isoprene was detected by sequentially monitoring masses $78 \mathrm{amu}\left(\mathrm{C}_{6} \mathrm{H}_{6}^{+}\right)$, $\left.156 \mathrm{amu}\left(\left(\mathrm{C}_{6} \mathrm{H}_{6}\right)_{2}^{+}\right)\right)$, and $146 \mathrm{amu}\left(\mathrm{C}_{5} \mathrm{H}_{8}^{+}\left(\mathrm{C}_{6} \mathrm{H}_{6}\right)\right)$ for integration times of $0.33 \mathrm{~s}, 0.33 \mathrm{~s}$, and $1.65 \mathrm{~s}$, respectively. For the conditions of this study, the ratio of the benzene dimer cation signal $(100 \mathrm{kHz})$ to the benzene monomer cation signal $(50 \mathrm{kHz})$ was $\sim 2: 1$. The isoprene signal was normalized to the sum of the reagent ion signals to account for variations in the ion source intensity. The sensitivity of the instrument was calibrated by performing standard additions of known amounts of isoprene to the inlet flow; calibration levels were 190, 1400, 2100, and 3100 pptv. The calibration gas was a gravimetrically prepared 10 ppmv mixture of isoprene in synthetic air (see below). The background at the isoprene product mass was measured by periodically overflowing the inlet with dry, isoprene free synthetic air (Scott Specialty Gases). Both, background determinations and calibrations were performed hourly. Mixing ratios of isoprene were obtained by subtracting the linearly interpolated background levels from the normalized isoprene signal and then dividing by the measured calibration factor. The calibration factor was of the order of $2 \mathrm{~Hz}$ per pptv of isoprene at a total reagent ion signal of $150 \mathrm{kHz}$. The measured background signals were $100-200 \mathrm{~Hz}$ with variations of less than $10 \mathrm{~Hz}$ within one day. The detection limit $(\mathrm{S} / \mathrm{N}=3)$ for these conditions was $21 \mathrm{pptv}$ for a $1 \mathrm{~s}$ integration period.

\subsection{GC}

The GC was housed in a separate trailer on the mesa. Air samples for the GC were drawn through a $3 \mathrm{~m}$ long $\times 1 / 4^{\prime \prime}$ OD Teflon tube at approximately 12 SLPM. The end of the tube was also located at a height of $\sim 2 \mathrm{~m}$ above the ground within $5 \mathrm{~m}$ of the CIMS inlet. The in situ GC method is described in detail elsewhere (Goldan et al., 2000) and is only briefly outlined here. The GC utilized a 70 SCCM (standard cubic centimeters per minute) fraction of the whole air sample stream, passed it through an Ascarite trap at ambient temperature that removed carbon dioxide and ozone and subsequently through a cold zone held at $-50^{\circ} \mathrm{C}$ to remove most of the water. Hydrocarbons in the sample stream were subsequently concentrated for a 5 minute period in a cold trap that consisted of a $0.53 \mathrm{~mm}$ ID $\times 20 \mathrm{~cm}$ long section of $\mathrm{Al}_{2} \mathrm{O}_{3}$ capillary column thermostatted at $-170^{\circ} \mathrm{C}$. The concentrated sample was then injected onto a $0.53 \mathrm{~mm}$ ID $\times 50 \mathrm{~m}$ long analytical column of the same material (Chrompack Inc.) by 

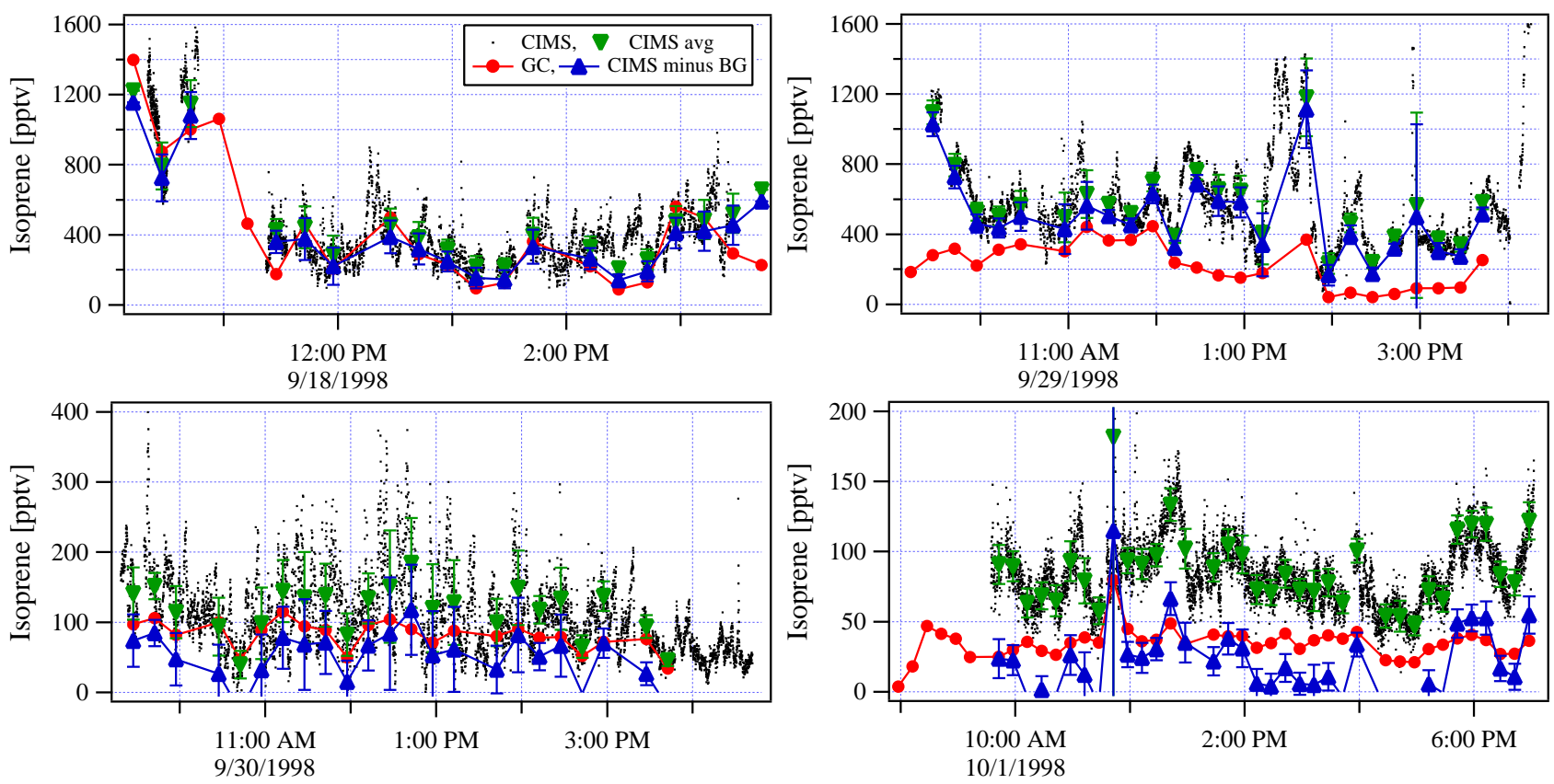

Fig. 2. Diurnal trends of isoprene measured with both instruments (CIMS: black dots, GC: red markers) during the intercomparison period as well as the CIMS data averaged (green markers) to the GC sampling periods. The CIMS background of about 70 pptv determined from Fig. 3 was substracted from the CIMS averages resulting in the CIMS net signal (blue markers). The error bars on the CIMS data represent the variability (standard deviation) of the CIMS data during the GC sampling interval. Time is Mountain Daylight Time (MDT).

heating the trap to $100^{\circ} \mathrm{C}$ in $\sim 6 \mathrm{~s}$. Analysis was performed with a hydrogen carrier gas at a flow rate of 4 SCCM while the column temperature was ramped from 75 to $150^{\circ} \mathrm{C}$ at a rate of $13^{\circ} \mathrm{C}$ per min. The detection limit for isoprene (defined as signal to noise ratio $=2$ ) was 5 pptv. The instrument had a 15 minute cycle time allowing the acquisition and analysis of 4 samples per h. Between samples, the water trap was heated to $50^{\circ} \mathrm{C}$ and both it and the Ascarite trap were flushed with hydrocarbon free "zero air" for cleaning. The sensitivity of the FID was calibrated using gravimetrically prepared calibration standards of isoprene in synthetic air at the $10 \mathrm{ppmv}$ level. For instrument calibration, these standards were diluted to the 0.1 to 2 ppbv range in a synthetic air matrix, to which ambient levels of carbon dioxide and water vapor were added, by a dynamic dilution system. The same gravimetrically prepared calibration standards were used by the CIMS instrument.

\subsection{Ancillary measurements}

Ancillary measurements of chemical species included NO (chemiluminescence), $\mathrm{NO}_{2}$ (photolytic conversion / chemiluminescence), total reactive nitrogen $\mathrm{NO}_{\mathrm{y}}$ (gold catalytic converter / chemiluminescence), and ozone (UV absorption). Wind speed and direction were also measured at the field site from a $10 \mathrm{~m}$ tower. The computer clocks for all the measurements were synchronized every morning and were found to deviate less than $5 \mathrm{~s}$ over the course of a day. Temper- ature, barometric pressure, and relative humidity were obtained from the Mesa Lab Weather Station (1855 m asl) at the National Center for Atmospheric Research located approximately $5 \mathrm{~km}$ south of Enchanted Mesa (NCAR, 1998).

\section{Results}

The CIMS and GC data were compared by averaging the individual $1.65 \mathrm{~s}$ CIMS data points over the corresponding 5 min GC sampling period. Figure 2 is a time series plot of the measurements obtained with both instruments as well as the time averaged CIMS data. The error bars on the averaged CIMS data represent the variability (standard deviation) of the CIMS isoprene measurements during the GC sampling period. Figure 3 shows the correlation of all averaged CIMS data with the individual GC measurements. While there is a good overall correlation $(R=0.78)$, the CIMS isoprene measurements clearly were consistently higher than those made with the GC. The linear regression of all CIMS vs. GC data has a positive intercept of $67 \mathrm{pptv}$ and a slope of 1.57 . Intercepts determined for the individual measurement days from 18 September to 01 October were $176 \mathrm{pptv}, 341 \mathrm{pptv}$, $4.5 \mathrm{pptv}$, and $12 \mathrm{pptv}$, respectively. These data strongly indicate that the CIMS method suffered from an interference that led to over-measurement of isoprene in addition to a potential background problem. In an attempt to characterize the interference, the normalized differences (ND) between the CIMS 


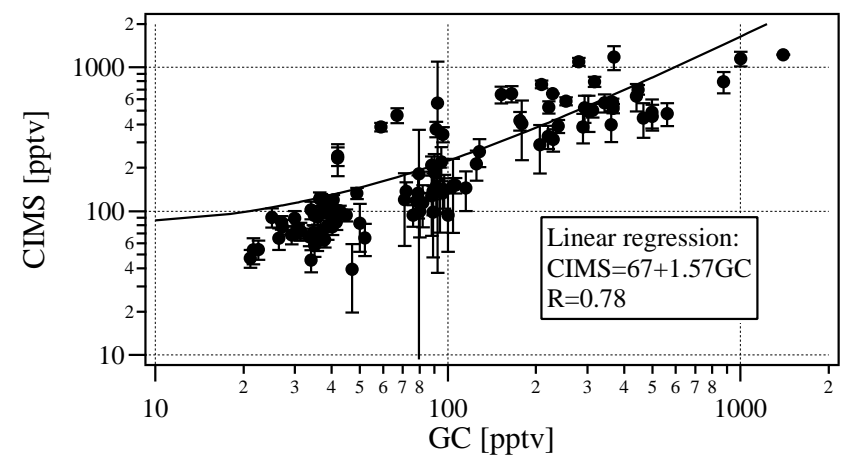

Fig. 3. Correlation of all GC measurements made during the intercomparison period with the averaged CIMS data. The error bars represent the standard deviation of the CIMS data during the GC sampling intervals. The solid line is the linear regression of CIMS vs. GC data, equation and correlation coefficient $R$ are given in the text box: The intercept of about 70 pptv indicates an enhanced background in the CIMS measurements.

and GC data were compared with both the chemical and meteorological ancillary measurements. The ND is a measure of the relative deviation between the measurements and is defined as:

$\mathrm{ND}=\frac{[\mathrm{CIMS}]-[\mathrm{GC}]}{\sqrt{[\mathrm{CIMS}][\mathrm{GC}]}}$,

where [CIMS] and $[\mathrm{GC}]$ are the concurrent isoprene measurements made by the CIMS and GC, respectively.

Of the meteorological parameters considered, the normalized differences were found to have a significant correlation only with wind direction (Fig. 4 and 5). Clearly, the ND was largest when the wind was from the south (Fig. 5). On 18 September, a day with relatively high concentrations and good correlation, there was no wind from southerly directions between 140 and $250^{\circ}$. On 29 September, however, when concentrations were similarly high, but correlation poorer, basically all directions were present. 30 September and 01 October, the two days with low isoprene concentrations, were dominated by northeasterly and northwesterly winds, respectively; no southerly directions were present at all. The CIMS isoprene measurements are also remarkably well correlated with $\mathrm{NO}_{\mathrm{x}}$ measurements $(R=0.7$, see Fig. 6) even though $\mathrm{NO}_{\mathrm{x}}$ and isoprene have very different sources. This suggests that the interfering compound to the CIMS measurements and nitrogen oxides were transported to the site from a collocated, anthropogenically influenced source. These findings clearly indicate that the main interference to the CIMS measurement was present in air masses transported from the Denver metropolitan area.

The high variation in the ND in the wind sector from 300 to $350^{\circ}$ may be due to an additional interference from the remote, forested areas in the northwest of our measurement site. We have demonstrated that 2-methyl-3-butene2-ol (MBO), a biogenic compound known to be emitted by
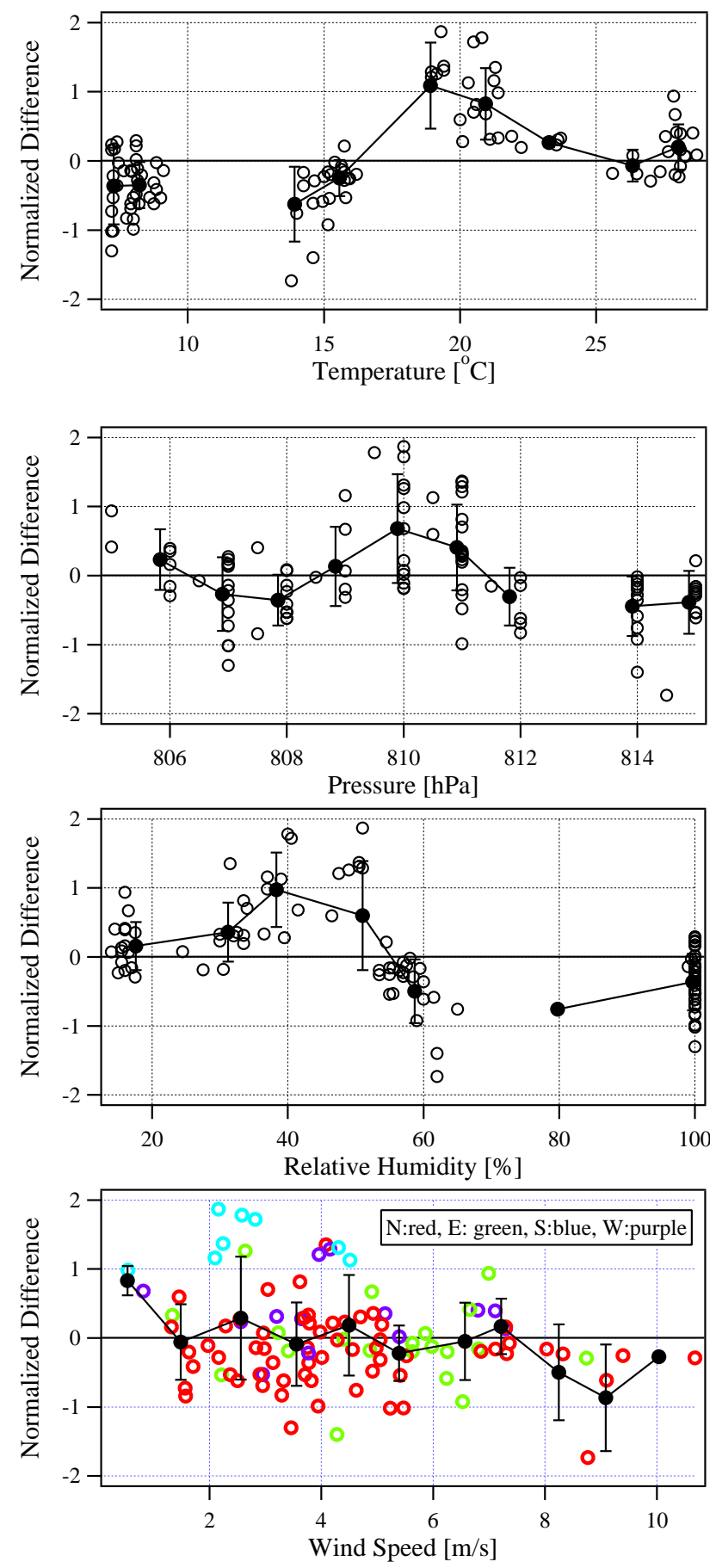

Fig. 4. Normalized differences of CIMS and GC data versus various meteorological parameters: temperature, pressure, relative humidity, wind speed, and wind direction. The CIMS data were averaged over the GC sampling time of $5 \mathrm{~min}$ and background corrected (open circles). To better visualize possible trends, the data were grouped into separate bins with a suitably chosen width and averaged within each bin (filled circles). The bars show the data variability (standard deviation) within each bin. Temperature, pressure, and relative humidity data were obtained from NCAR (1998). 


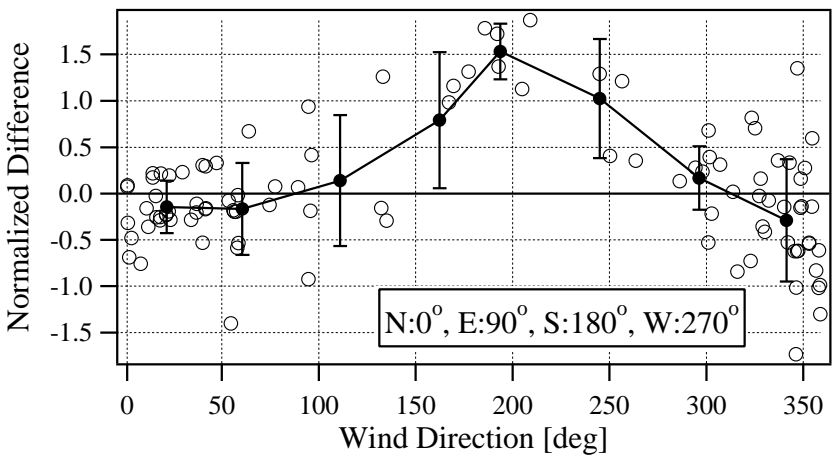

Fig. 5. Normalized differences of CIMS and GC data versus wind direction $\left(0^{\circ}=\mathrm{N}, 90^{\circ}=\mathrm{E}, 180^{\circ}=\mathrm{S}, 270^{\circ}=\mathrm{W}\right)$.

North American pine forests (Goldan et al., 1993; Harley et al., 1998; Schade et al., 2000) interferes with our isoprene measurement (Leibrock and Huey, 2000). However, without the use of a tandem technique, we cannot yet determine the exact nature of the interfering species.

\section{Conclusions}

Unfortunately, the data obtained in this study demonstrate that the CIMS technique in its present form is not a viable method for isoprene measurements in or near an urban environment unless there are high levels of isoprene present. This is likely due to unidentified components that also react with the benzene reagent ions to give the same product mass as isoprene.

Basically, any compound with mass $68 \mathrm{amu}$ and an ionization potential of less than $9.1 \mathrm{eV}$ is likely to interfere with our technique. We have demonstrated that $\mathrm{C}_{5} \mathrm{H}_{8}$ conjugated dienes (such as $t-1,3$-pentadiene) and 2-methyl-3-butene-2ol (MBO) also react with $\mathrm{C}_{6} \mathrm{H}_{6}^{+}$and $\left(\mathrm{C}_{6} \mathrm{H}_{6}\right)_{2}^{+}$to give mass 146 (Leibrock and Huey, 2000). However, we could not yet determine if these actually were the interfering species in this work. This study thus demonstrates the largest difficulty with measurements of VOCs by positive ion chemical ionization: the ambient mix of organic compounds in polluted air is so complex that it is difficult for ion chemistry to selectively detect a tractable number of compounds.

The conditions of this intercomparison were very challenging for the CIMS method because of the low isoprene mixing ratios (less than $1 \mathrm{ppbv}$ for most of the time) and the complex mix of VOC at the site due to local urban sources. These considerations suggest that the present CIMS isoprene method may be a viable technique for measurements in remote areas with high isoprene emissions and little anthropogenic influence. Sensitivity and time response of the technique were also clearly demonstrated in this study (Fig. 2).

One improvement to enhance the selectivity of the current technique would be the replacement of the quadrupole mass
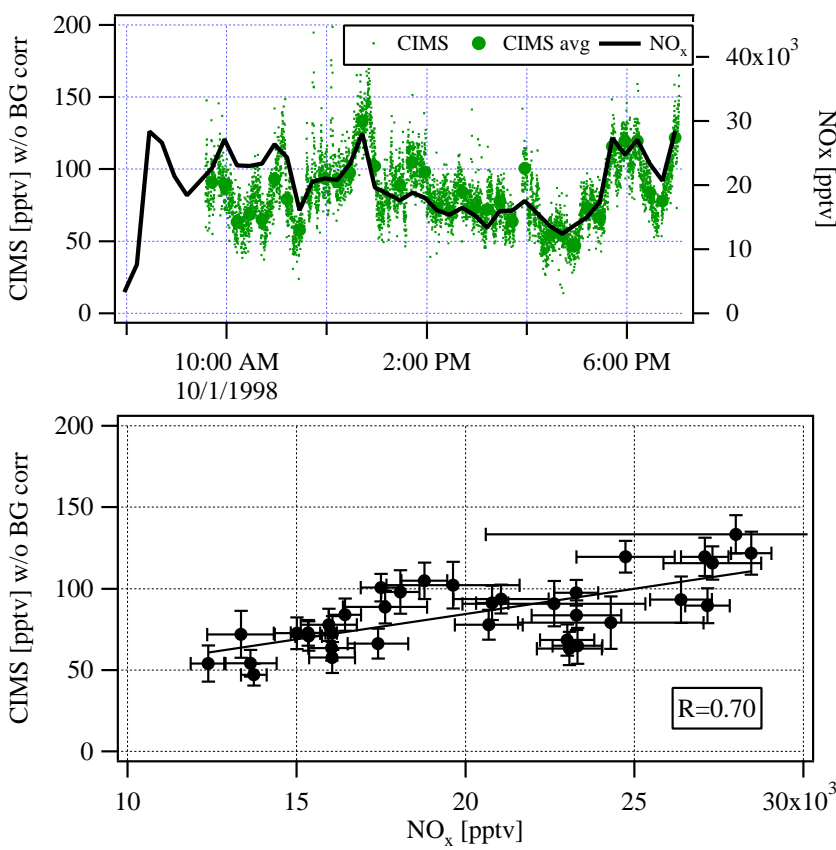

Fig. 6. The upper panel shows diurnal trends (01 October 1998) of non-background corrected isoprene data measured with the CIMS and their 5-min averages (left axis) and $\mathrm{NO}_{\mathrm{x}}$ (right axis) based on measurements of $\mathrm{NO}$ and $\mathrm{NO}_{2}$ with a time resolution of $1 \mathrm{~s}$ each, suggesting a correlation between the data shown. The lower panel shows the linear correlation of the averaged, non-background corrected CIMS data versus the corresponding 5-min averages of the $\mathrm{NO}_{\mathrm{x}}$ values.

filter with a system that is capable of tandem mass spectrometry such as an ion trap mass spectrometer, (e.g. Dawson, 1976; March and Hughes, 1989). This would add another level of selectivity and allow to differentiate between isoprene and compounds that form products with equal masses, but have different internal structures.

Acknowledgements. E. L. was supported by a research grant by the German Academic Exchange Service (DAAD).

\section{References}

Arnold, F. and Hauck, G.: Lower stratosphere trace gas detection using aircraft-borne active chemical ionization mass spectrometry, Nature, 315, 307-309, 1985.

Atkinson, R.: Gas-phase tropospheric chemistry of organic compounds, Atmos. Environ., 24, 1-41, 1990.

Dawson, P. H.: Quadrupole mass spectrometry and its application, Elsevier, Amsterdam, 1976.

Eisele, F. L., Mount, G. H., Fehsenfeld, F. C., Harder, J., Marovich, E., Roberts, J., Tanner, D. J., and Trainer, M.: An intercomparison of tropospheric $\mathrm{OH}$ and ancillary trace gas measurements at Fritz Peak Observatory, Colorado, J. Geophys. Res., 99, 18 605, 1994. 
Fehsenfeld F., Calvert, J., Fall, R., Goldan, P., Guenther, A. B., Hewitt, C. N., Lamb, B., Liu, S., Trainer, M., Westberg, H., and Zimmerman, P.: Emissions of volatile organic compounds from vegetation and the implications for atmospheric chemistry, Global Biogeochemical Cycles, 6, 389-430, 1992.

Fehsenfeld, F. C., Huey, L. G., Sueper, D. T., Norton, R. B., Williams, E. J., Eisele, F. L., Mauldin, III, R. L., and Tanner, D. J.: Ground-based intercomparison of nitric acid measurement techniques, J. Geophys. Res., 103, 3343-3353, 1998.

Goldan, P. D., Kuster, W. C., Fehsenfeld, F. C., and Montzka, S. A.: The observation of a $\mathrm{C}_{5}$ alcohol emission in a North American pine forest, Geophys. Res. Lett., 20, 1039-1042, 1993.

Goldan, P. D., Parrish, D. D., Kuster, W. C., Trainer, M., McKeen, S. A., Holloway, J., Jobson, B. T., and Sueper, D. T.: Airborne measurements of isoprene, $\mathrm{CO}$, and anthropogenic hydrocarbons and their implications, J. Geophys. Res., 105, 9091-9105, 2000.

Hansel A., Jordan, A., Holzinger, R., Prazeller, P., Vogel, W., and Lindinger, W.: Proton transfer reaction mass spectrometry: online trace gas analysis at the ppb level, Int. J. Mass Spec. Ion Processes, 149/150, 609-619, 1995.

Harley, P., Fridd-Stroud, V., Greenberg, J., Guenther, A., and Vasconcellos, P.: Emission of 2-methyl-3-buten-2-ol by pines: A potentially large natural source of reactive carbon to the atmosphere, J. Geophys. Res., 103, 25 479-25 486, 1998.

Huey, L. G. and Lovejoy, E. R.: Reactions of $\mathrm{SiF}_{5}{ }^{-}$with atmospheric trace gases: ion chemistry for chemical ionization detection of $\mathrm{HNO}_{3}$ in the troposphere, Int. J. Mass Spec. Ion Processes, 155, 133-140, 1996.

Leibrock, E. and Huey, L. G.: Ion chemistry for the detection of isoprene and other volatile organic compounds in ambient air,
Geophys. Res. Lett., 27, 1719-1722, 2000.

Lindinger, W. and Hansel, A.: Analysis of trace gases at ppb levels by proton transfer reaction mass spectrometry (PTR-MS), Plasma Sources Sci. Technol., 6, 111-117, 1997.

March, R. E. and Hughes, R. J.: Quadrupole storage mass spectrometry, John Wiley \& Sons, New York, NY, 1989.

Montzka, S. A., Trainer, M., Goldan, P. D., Kuster, W. C., and Fehsenfeld, F. C.: Isoprene and its oxidation products, methyl vinyl keton and methacrolein in the rural troposphere, J. Geophys. Res. 98, 1101-1111, 1993.

NCAR: Mesa Lab Weather Station Data, via anonymous ftp from atd.ucar.edu/pub/weather/mesa/, 1998

Schade, G., Goldstein, A., Gray, D., and Lerdau, M.: Whole ecosystem and leaf level 2-methyl-3-buten-2-ol fluxes from a ponderosa pine plantation, Atmos. Env. 34, 3535-3544, 2000.

Singh, H. B. and Zimmerman, P. B.: Atmospheric distribution and sources of nonmethane hydrocarbons, in: Gaseous Pollutants: characterization and cycling, (Ed) Nriagu, J. O. , pp. 177-235, John Wiley \& Sons, New York, NY, 1992.

Steinbrecher, R.: Isoprene: Production by plants and ecosystemlevel estimates, in: Biogenic volatile organic carbon compounds in the atmosphere, (Eds) Helas, G., Slanina, J., and Steinbrecher, R., pp. 101-114, SPB Academic Publishing, Amsterdam, The Netherlands. 1997.

Williams, E. J., Sandholm, S. T., Bradshaw, J. D., Schendel, J. S., Langford, A. O, Quinn, P. K., LeBel, P. J., Vay, S. A., Roberts, P. D., Norton, R. B., Watkins, B: A., Buhr, M. P., Parrish, D. D., Calvert, J. G., and Fehsenfeld, F. C.: An intercomparison of five ammonia measurement techniques, J. Geophys. Res., 97, $11591-11611,1992$. 